\title{
THE TITRATION OF WASSERMANN REAGENTS *
}

\author{
LOYD THOMPSON, M.D. \\ LITTLE BOCK, ARK.
}

As the Wassermann test is considered, and should be, a quantitative reaction, the correct titration of the reagents, especially complement and amboceptor, is of the utmost importance.

Wassermann, ${ }^{1}$ in the original communication, and Noguchi, ${ }^{2}$ as well as other writers on the subject, recommend the titration of complement and amboceptor without the addition of the other factors. That is, these two factors are mixed in varying quantities with a suspension of corpuseles. On incubation the smallest amount of the factor which, with a fixed quantity of the other, is required to produce complete hemolysis, is considered as one unit. For the actual test twice the unit is used.

This method of titration is open to objection. Noguchi has pointed out that within certain limits complement and amboceptor are interchangeable. Further, it is a recognized fact that on the addition of patients' serum (whether positive or negative) or antigen, more complement or amboceptor is required to produce hemolysis than when neither of these factors is added. This is overcome by doubling the units of complement and amboceptor.

The objection is that the worker does not know that twice the amount of complement and amboceptor which are required to produce hemolysis without serum and antigen will just produce hemolysis with them; that is, of course, if the serum is from a non-luetic patient, and the worker does not know that, when just a small amount of the complement present is bound by a slightly positive serum, enough complement may be left to produce complete hemolysis, and a weakly positive test be changed to a negative.

The following method of titration of complement and amboceptor has been adopted by me in my Wassermann work:

Actual test conditions are imposed on the factors throughout. The human hemolytic system is employed. The method of preparing the reagents has been described in a previous article. ${ }^{3}$

* Submitted for publication Dec. 8, 1913.

* From the Laboratory of Clinical Diagnosis, Medical Department, University of Arkansas.

1. Deutsch. med. Wchnschr., 1906, xxxii, 745.

2. Noguchi, H.: The Serum Diagnosis of Syphilis, Philadelphia, 1911.

3. Thompson, Loyd Oscar: A Modified Wassermann, The ARchives Int. Med., 1913, xi, 512 . 
The corpuscle suspension is a 2.5 per cent. solution of washed human erythrocytes. The complement is a 10 per cent. solution of guinea-pig serum, while the amboceptor is a solution of the serum of a rabbit, which has been immunized to human corpuscles, and diluted according to the titrated value.

The corpuscle suspension is, of course, fixed and when amboceptor is titrated, it is necessary first to titrate the complement to be used against a known amboceptor, or to fix the dose of complement arbitrarily. The latter is the usual method and $I$ choose 0.5 c.c. as the most common unit.

Fifteen tubes are required for the titration of amboceptor and eight tubes for controls. The controls are the same as those used in the actual test. In each of the fifteen tubes is placed 0.1 c.c. of a known negative inactivated serum, 0.5 c.c. of complement, 1 unit of antigen (diluted so that 1 unit $=0.1$ c.c.), and the amount of physiological salt solution required to bring the total volume up to 2.5 c.c., as indicated in Table 1.

TABLE 1.-Titration OF AMBoceptor

\begin{tabular}{|c|c|c|c|c|c|c|c|c|}
\hline Tube & Serum & Comp. & Ant. & $\mathrm{NaCl}$ & Amboceptor & Corp. & Total & Results \\
\hline 1 & 0.1 & 0.5 & 0.1 & 0.8 & 0.5 of $1: 10,000$ & 0.5 & 2.5 & NH \\
\hline 2 & 0.1 & 0.5 & 0.1 & 0.7 & 0.6 of $1: 10,000$ & 0.5 & 2.5 & $\mathrm{NH}$ \\
\hline $\mathbf{3}$ & 0.1 & 0.5 & 0.1 & 0.6 & 0.7 of $1: 10,000$ & 0.5 & 2.5 & $\mathrm{PH}$ \\
\hline 4 & 0.1 & 0.5 & 0.1 & 0.5 & 0.8 of $1: 10,000$ & 0.5 & 2.5 & $\mathbf{P H}$ \\
\hline 5 & 0.1 & 0.5 & 0.1 & 0.4 & 0.9 of $1: 10,000$ & 0.5 & 2.5 & $\mathrm{PH}$ \\
\hline 6 & 0.1 & 0.5 & 0.1 & 1.2 & 0.1 of $1: 1,000$ & 0.5 & 2.5 & PH \\
\hline 7 & 0.1 & 0.5 & 0.1 & 1.1 & 0.2 of $1: 1,000$ & 0.5 & 2.5 & $\mathbf{P H}$ \\
\hline 8 & 0.1 & 0.5 & 0.1 & 1.0 & 0.3 of $1: 1,000$ & 0.5 & 2.5 & $\mathbf{H}$ \\
\hline 9 & 0.1 & 0.5 & 0.1 & 0.9 & 0.4 of $1: 1,000$ & 0.5 & 2.5 & $\mathrm{H}$ \\
\hline 10 & 0.1 & 0.5 & 0.1 & 0.8 & 0.5 of $1: 1,000$ & 0.5 & 2.5 & $\mathbf{H}$ \\
\hline Il & 0.1 & 0.5 & 0.1 & 0.7 & 0.6 of $1: 1,000$ & 0.5 & 2.5 & $\mathbf{H}$ \\
\hline 12 & 0.1 & 0.5 & 0.1 & 0.6 & 0.7 of $1: 1,000$ & 0.5 & 2.5 & $\mathbf{H}$ \\
\hline 13 & 0.1 & 0.5 & 0.1 & 0.5 & 0.8 of $1: 1,000$ & 0.5 & 2.5 & $\mathbf{H}$ \\
\hline 14 & 0.1 & 0.5 & 0.1 & 0.4 & 0.9 of $1: 1,000$ & 0.5 & 2.5 & $\mathbf{H}$ \\
\hline 15 & 0.1 & 0.5 & 0.1 & 0.3 & 1.0 of $1: 1,000$ & 0.5 & 2.5 & $\mathbf{H}$ \\
\hline 16 & 0.0 & 0.5 & 0.0 & 0.5 & 1.0 of $1: 1,000$ & 0.5 & 2.5 & $\mathrm{H}$ \\
\hline 17 & 0.0 & 0.5 & 0.1 & 0.4 & 1.0 of $1: 1,000$ & 0.5 & 2.5 & $\mathbf{H}$ \\
\hline 18 & 0.0 & 0.5 & $0 . \mathrm{I}$ & 1.4 & 0.0 & 0.5 & 2.5 & NH \\
\hline 19 & 0.0 & 0.5 & 0.0 & 1.5 & 0.0 & 0.5 & 2.5 & NH \\
\hline 20 & 0.0 & 0.0 & 0.1 & 0.9 & 1.0 of $1: 1,000$ & 0.5 & 2.5 & $\mathrm{NH}$ \\
\hline 21 & 0.0 & 0.0 & 0.1 & 1.9 & 0.0 & 0.5 & 2.5 & NH \\
\hline 22 & 0.0 & 0.0 & 0.0 & 1.0 & 1.0 of $1: 1,000$ & 0.5 & 2.5 & $\mathrm{NH}$ \\
\hline 23 & 0.0 & 0.0 & 0.0 & 2.0 & 0.0 & 0.5 & 2.5 & $\mathrm{NH}$ \\
\hline
\end{tabular}

The tubes are now incubated one hour in the incubator or half an hour in the water-bath at $37 \mathrm{C}$., after which the amboceptor and corpuscles are added.

Tube 1 contains 0.5 c.c. of a $1: 10,000$ dilution of amboceptor and the amount is increased until Tube 15 contains 1 c.c. of a $1: 1,000$ dilution, or 0.01 c.c. of pure serum. The incubation is continued two hours in the incubator, or one hour in the water-bath at $37 \mathrm{C}$. At the end of this time the tube which contains the least amboceptor, which shows com- 
plete hemolysis, is determined and this amount of amboceptor is considered as 1 unit.

The titration of complement is similar except that here the amboceptor is the fixed quantity and the tubes contain increasing amounts of complement, as indicated in Table 2.

TABLE 2.-Titration OF Complement

$\begin{array}{ccccccccc}\text { Tube } & \text { Ser. } & \text { Comp. } & \text { Ant. } & \text { NaCl } & \text { Amb. } & \text { Corp. } & \text { Total } & \text { Results } \\ 1 & 0.1 & 0.4 & 0.1 & 1.3 & 0.1 & 0.5 & 2.5 & \text { PH } \\ 2 & 0.1 & 0.5 & 0.1 & 1.2 & 0.1 & 0.5 & 2.5 & \text { PH } \\ 3 & 0.1 & 0.6 & 0.1 & 1.1 & 0.1 & 0.5 & 2.5 & \text { PH } \\ 4 & 0.1 & 0.7 & 0.1 & 1.0 & 0.1 & 0.5 & 2.5 & \text { H } \\ 5 & 0.1 & 0.8 & 0.1 & 0.9 & 0.1 & 0.5 & 2.5 & \text { H } \\ 6 & 0.1 & 0.9 & 0.1 & 0.8 & 0.1 & 0.5 & 2.5 & \text { H } \\ 7 & 0.1 & 1.0 & 0.1 & 0.7 & 0.1 & 0.5 & 2.5 & \text { H } \\ 8 & 0.0 & 1.0 & 0.0 & 0.9 & 0.1 & 0.5 & 2.5 & \text { H } \\ 9 & 0.0 & 1.0 & 0.1 & 0.8 & 0.1 & 0.5 & 2.5 & \text { NH } \\ 10 & 0.0 & 1.0 & 0.1 & 0.9 & 0.0 & 0.5 & 2.5 & \text { NH } \\ 11 & 0.0 & 1.0 & 0.0 & 1.0 & 0.0 & 0.5 & 2.5 & \text { NH } \\ 12 & 0.0 & 0.0 & 0.1 & 1.8 & 0.1 & 0.5 & 2.5 & \text { NH } \\ 13 & 0.0 & 0.0 & 0.1 & 1.9 & 0.0 & 0.5 & 2.5 & \text { NH } \\ 14 & 0.0 & 0.0 & 0.0 & 1.9 & 0.1 & 0.5 & 2.5 & \text { NH } \\ 15 & 0.0 & 0.0 & 0.0 & 2.0 & 0.0 & 0.5 & 2.5 & \end{array}$

In the actual performance of the test, one unit each of complement and amboceptor, and only one, is used. This is all that is required, since it has been determined that, with these amounts, we have secured complete hemolysis with a known negative serum, and if, with an unknown serum, we get any inhibition of hemolysis, we know that something has bound at least part of the complement, which indicates a positive reaction.

In the titration of antigen the first and most important point is to determine whether or not the antigen is hemolytic in an amount considerably in excess of the antigenic unit. This is determined by adding to a corpuscle suspension gradually increasing amounts of the antigen, as indicated in Table 3.

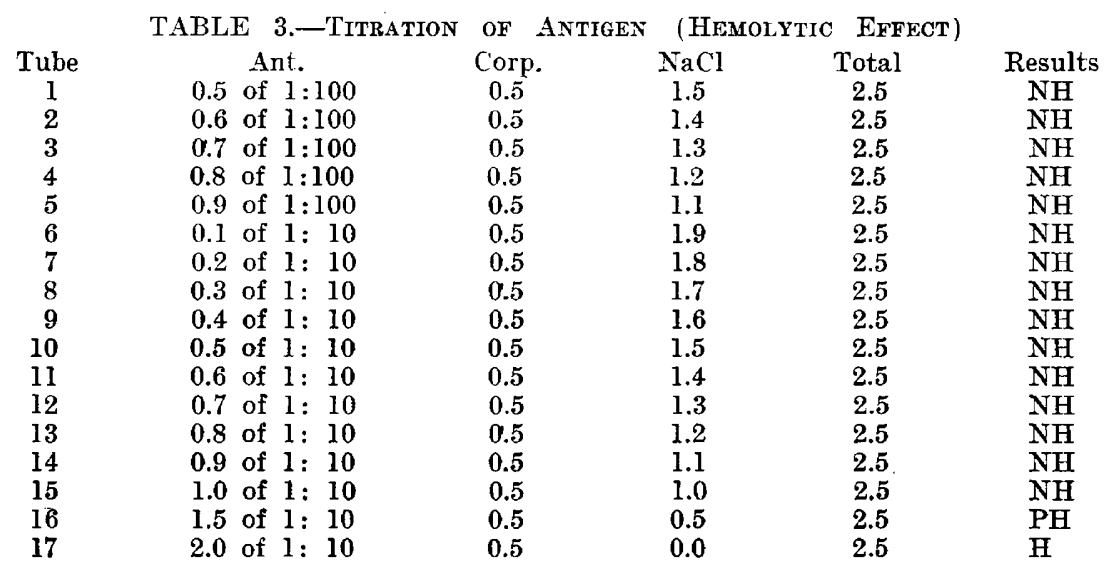


Tube 1 contains 0.5 c.c. of a $1: 100$ dilution of antigen, while Tube 17 contains 2 c.c. of a $1: 10$ dilution, or 0.2 c.c. of pure antigen.

The tubes are now incubated for one hour in the water-bath at $37 \mathrm{C}$., and the one containing the largest amount of antigen in which there is no hemolysis is recorded.

Working with Dr. Gabby of the Psychopathic Institute at Kankakee, Ill., and Dr. Nichols of the Presbyterian Hospital, Chicago, I have shown that certain antigens, which have a marked hemolytic action when added to corpuscles alone, have this action inhibited when either human or guinea-pig serum is added in small quantity ( 0.1 c.c.).

The question naturally presents itself, whether or not such an antigen would be a safe one to use, since antigen is never used in a test without the presence of patients' serum and complement. I do not consider it safe, because if it is used, and the corpuscles are hemolyzed, it would not be known how much of the hemolysis is due to the amboceptor and complement, and how much to the antigen.

TABLE 4.-Titration of Antigen (Anticomplementary Value)

$\begin{array}{cccccccccc}\text { Tube } & \text { Ser. } & \text { Comp. } & \text { Ant. } & \text { NaCl } & \text { Amb. } & \text { Corp. } & \text { Total } & \text { Results } \\ 1 & 0.1 & 0.5 & 0.5 \text { of } 1: 100 & 0.8 & 0.1 & 0.5 & 2.5 & \text { H } \\ 2 & 0.1 & 0.5 & 0.6 \text { of } 1: 100 & 0.7 & 0.1 & 0.5 & 2.5 & \text { H } \\ 3 & 0.1 & 0.5 & 0.7 \text { of } 1: 100 & 0.6 & 0.1 & 0.5 & 2.5 & \text { H } \\ 4 & 0.1 & 0.5 & 0.8 \text { of } 1: 100 & 0.5 & 0.1 & 0.5 & 2.5 & \text { H } \\ 5 & 0.1 & 0.5 & 0.9 \text { of } 1: 100 & 0.4 & 0.1 & 0.5 & 2.5 & \text { H } \\ 6 & 0.1 & 0.5 & 0.1 \text { of } 1: 10 & 1.2 & 0.1 & 0.5 & 2.5 & \text { H } \\ 7 & 0.1 & 0.5 & 0.2 \text { of } 1: 10 & 1.1 & 0.1 & 0.5 & 2.5 & \text { H } \\ 8 & 0.1 & 0.5 & 0.3 \text { of } 1: 10 & 1.0 & 0.1 & 0.5 & 2.5 & \text { H } \\ 9 & 0.1 & 0.5 & 0.4 \text { of } 1: 10 & 0.9 & 0.1 & 0.5 & 2.5 & \text { H } \\ 10 & 0.1 & 0.5 & 0.5 \text { of } 1: 10 & 0.8 & 0.1 & 0.5 & 2.5 & \text { H } \\ 11 & 0.1 & 0.5 & 0.6 \text { of } 1: 10 & 0.7 & 0.1 & 0.5 & 2.5 & \text { H } \\ 12 & 0.1 & 0.5 & 0.7 \text { of } 1: 10 & 0.6 & 0.1 & 0.5 & 2.5 & \text { H } \\ 13 & 0.1 & 0.5 & 0.8 \text { of } 1: 10 & 0.5 & 0.1 & 0.5 & 2.5 & \text { H } \\ 14 & 0.1 & 0.5 & 0.9 \text { of } 1: 10 & 0.4 & 0.1 & 0.5 & 2.5 & \text { H } \\ 15 & 0.1 & 0.5 & 1.0 \text { of } 1: 10 & 0.3 & 0.1 & 0.5 & 2.5 & \text { PH }\end{array}$

The second point to be determined is the anticomplementary effect of the antigen. In a good antigen this effect must not be evident in an amount considerably greater than the antigenic unit. A series of fifteen tubes is arranged as in Table 4, 0.1 c.c. of a known negative, inactivated serum is placed in each tube, one unit of previously titrated complement (usually 0.5 c.c.), increasing amounts of the antigen and enough salt solution to bring the total volume, when amboceptor and corpuscles are added, to 2.5 c.c. The tubes are now incubated for half an hour in the water-bath at $37 \mathrm{C}$, after which one unit of previously titrated amboceptor and 0.5 c.c. of corpuscles are added and the incubation continued for one hour. The tube which contains the largest amount of antigen in which hemolysis is complete is recorded.

The next and final point in the titration of antigen is the determination of the antigenic unit. This titration is identical with the determi- 
nation of the anticomplementary value, except that instead of using a known negative serum, a known positive serum is employed. In fact, these two titrations may be, and usually are, carried out at one time. After the final incubation the tubes are placed in the ice-box for a few hours, when the tube is determined which contains the smallest amount of antigen in which inhibition of hemolysis is complete.

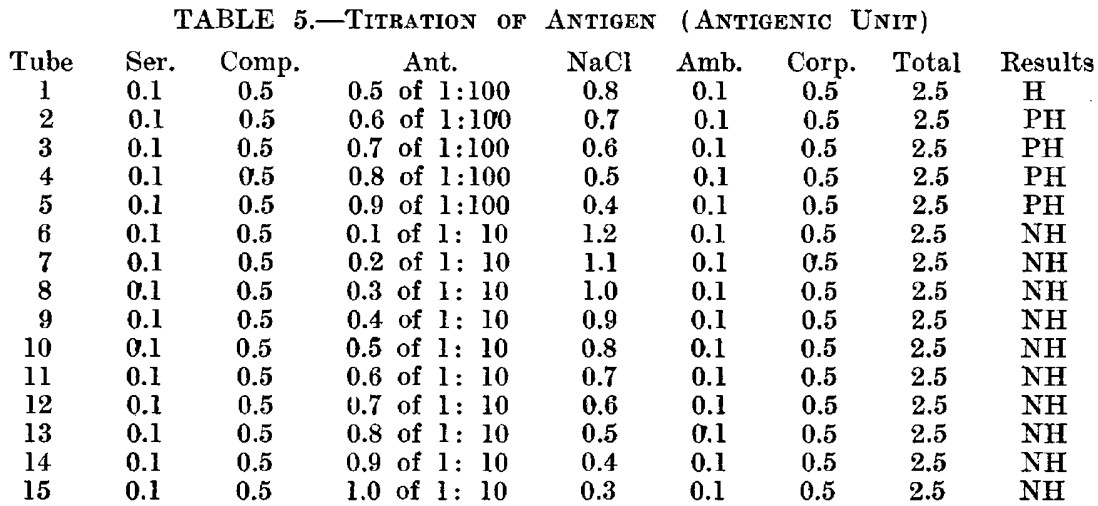

The antigenic unit is that amount of antigen which is the average of the smallest amount which will completely inhibit hemolysis with a known positive serum, and the largest amount which will cause no inhibition with a known negative serum. For example, if we have found that 0.1 c.c. of the $1: 10$ dilution of antigen completely inhibits the hemolysis with a known positive serum, and 0.9 c.c. of antigen is the largest amount which does not inhibit hemolysis with a known negative serum, 0.5 c.c. is the antigenic unit. 